How Meeting Centres continue to support people affected by dementia: report on UK COVID-19 impact

\begin{tabular}{|r|l|}
\hline Journal: & Working with Older People \\
\hline Manuscript ID & WWOP-12-2020-0060 \\
\hline Manuscript Type: & Research Paper \\
\hline Keywords: & $\begin{array}{l}\text { older people, well-being, social care, vulnerability, social inclusion, } \\
\text { quality of life }\end{array}$ \\
\hline
\end{tabular}

SCHOLARONE ${ }^{\text {m }}$

Manuscripts 


\title{
How Meeting Centres continue to support people affected by dementia: report on UK COVID-19 impact
}

\begin{abstract}
Purpose: Due to COVID-19 restrictions, Meeting Centres (MCs) for people affected by dementia in the UK, ceased to meet physically but continued to provide remote support. The aim was to understand the extent to which MCs were able to operate when physical meetings were not possible and how they achieved particularly in relation to the Adaptation and Coping Model and practical, emotional and social adjustment.
\end{abstract}

Design: Semi-structured interviews and focus groups were conducted with people affected by dementia, staff, volunteers, managers and trustees from MCs. Data were collected on the type and quantity of contact MCs had with people affected by dementia during lockdown. Data were coded and mapped against adaptation and coping strategies i.e. practical understanding and empowerment, optimising emotional well-being and opportunities for social engagement.

Findings: A range of remote approaches, both technological (eg. using online platforms) and non-technological (eg. newsletters and post) were implemented alongside limited face-to-face contact. Regular MC activities were adapted using the different approaches. It was possible to map all the Adaptation and Coping model support strategies to the activities delivered in this way. MCs were able to adapt rapidly to continue to support people to adjust to change.

Social implications: Moving forwards, combining approaches (usual MC and remote) means person-centred support could be optimised, addressing social isolation and reaching those who cannot attend MCs. 
Originality: This article offers new insight into the extent to which community-based support for people with dementia can continue when face to face contact is not possible due to COVID-19.

Keywords: dementia; COVID-19; community-based support; Adaptation and Coping Model; adjusting to change; social isolation

Running title: Meeting Centres support during COVID-19

\section{Introduction}

In usual times people with dementia are amongst the most vulnerable in our communities. The pandemic has increased this vulnerability due to both the morbidity and mortality from COVID-19 and the indirect effects of the pandemic on the health and social care system on which they depend. People affected by dementia become increasingly dependent on the health and social care systems which are themselves stretched to their limits in dealing with the pandemic (Brown et al., 2020; Canevelli et al., 2020; Giebel et al., 2020).

A recent survey (Alzheimer's Society, 2020) showed that COVID-19 restrictions have had particularly negative impacts on the health and well-being of people affected by dementia in the UK. $46 \%$ of people reported that lockdown had a negative impact on their mental health and in a wider group that included caregivers, $82 \%$ reported a deterioration in the symptoms of people with dementia. 
Meeting Centres (MCs) are a community-based post-diagnostic intervention for people with mild to moderate dementia and family caregivers living at home. MCs originated in the Netherlands (Dröes et al., 2004a; Dröes et al., 2004b; Dröes et al., 2011). The MEETINGDEM research programme (www.meetingdem.eu) implemented and evaluated the Dutch MC model in the UK, Italy and Poland and assessed what adaptations were necessary. The research demonstrated good evidence that MCs help people, their families and communities build resilience for the longer term (Brooker et al., 2018; Evans et al., 2018; Mazurek et al., 2019; Szcześniak et al., 2019).

In usual times MCs are places where people with dementia and their family can regularly and routinely socialise, take part in activities and get support. At the heart of MCs is a small social club (15 people with dementia per day plus family caregivers), based in an ordinary community building, close-by to where people live. MCs operate up to three times per week, providing people with dementia and family caregivers the chance to build friendships, engage in peer support, understand their problems, get help and prepare for the future. They are facilitated by a small team of paid staff alongside a group of volunteers. Evidence-based post diagnostic interventions are provided in a friendly manner, geared to the needs of people with dementia and facilitated by a small team of staff and volunteers. A programme of activities for both people with dementia and family caregivers, facilitated face to face, takes place based on the wishes of people with dementia and family caregivers and will include movement and co-ordination (for example seated exercise, tea dances, gardening and walks), talks by people with dementia or family caregivers or people from the community, visits to local attractions and heritage sites, quizzes, 
discussions and arts and crafts activities. Regular family caregiver meetings take place and serve as an opportunity to engage in peer support and learn about dementia. The use of technology is relatively limited.

All the features of a MC are geared up to help people make the best emotional, social and practical adjustments to living with dementia. Staff and volunteers are trained in person-centred dementia care and the Adaptation-Coping model. This model has its theoretical origins in the stress-appraisal coping model of Lazarus and Folkman (1984). Dröes et al. (2010) developed this model as a framework for understanding mood and behaviour difficulties in people with mild to moderate dementia.

In the UK MCs, Adaptation and Coping is also known as the Adjusting to Change model. The domain names were re-named as practical, emotional and social adjustment. This translation is illustrated in Figure 1 together with related support strategies which will vary depending on each individual person and family (Brooker et al., 2017).

---Insert Figure 1 here---

\section{Fig 1 UK translation into the 'Adjusting to Change Model'}

Due to the pandemic all MCs had to close their doors on 23rd March 2020 and all face to face support ceased. This provided an opportunity to gain an understanding of the extent to which MCs are able to operate when physical meetings are not possible. 


\section{Methods}

\section{Study Design}

The research focused on the four UK MC demonstrator sites. All these MCs were already enrolled into on-going data collection as part of a wider research project on UK MCs. A decision was made to change the focus of the research to gain insight into the impact of lockdown.

Data was collected for the period 23/03/20-30/06/20, on the type and quantity of contact they had with people with dementia and family caregivers during lockdown. Recruitment of participants for both the semi-structured interviews and the focus groups was facilitated by the relevant MC manager at each MC. Participants were invited and went through an ethically approved consent procedure.

The aim was to recruit up to six people with dementia and/or family caregivers, the manager, one member of staff or volunteer and one trustee from each MC. Semistructured interviews were conducted via telephone and were recorded. People with dementia and family caregivers were asked about the type of support they receive in usual times, what support they had received since lockdown from the MC, what impact this had and what other support they were receiving from the community. Staff, volunteers, managers and trustees were asked specifically about how they were supporting people with dementia and family caregivers to adjust to change and whether they thought they had the skills to adapt to the current and changing situation and where there might be a need for training and development. 
In addition to the interviews, the aim was to conduct across MCs, via video conferencing software, a focus group, of six people for each of the following groups: - people with dementia and family caregivers, staff and volunteers and managers and trustees. Zoom was chosen as the video conferencing software as all MC managers were familiar with it. Interviews were designed to last up to one hour using the relevant questions for those indicated above as a framework.

\section{Data Analysis}

Descriptive analysis was used to calculate the total numbers of different types of contact across the period in question. Qualitative data were transcribed. The content was coded against the 'Support Strategies' listed in The UK translation into the Adjusting to Change Model (Figure 1).

\section{Ethical Permissions}

Ethics approval, including an appropriate process for involving people living with dementia who were not able to provide informed consent was sought from and granted by the University of Worcester Ethics Health, Life \& Environmental Sciences (CHLES REP) Research Ethics Panel Committee, 5th April 2020, REP CODE: CHLES18190018-R amended 5th May 2020.

\section{Results}

\section{Types of contact}

During the lockdown period, the four MCs reported supporting 76 people living with dementia and 72 family caregivers through the type of contacts detailed in Table I below. The data presented in Table I are based on the information reported and 
should be considered as an under-representation of the actual level of activity taking place.

---Insert Table I here---

Most contact was via email. A significant amount of contact was carried out via traditional modes of engaging i.e. via telephone, post and home garden visits. Zoom, WhatsApp and FaceTime were used to a lesser extent because (according to MC Managers) a minority of people with dementia and family caregivers did not have the relevant technology and/or skills to participate.

\section{Interviews and Focus Groups}

We interviewed 28 stakeholders and conducted 6 focus groups as detailed in Table II.

---Insert Table II here---

Data are presented below to illustrate the support strategies set out under the Adjusting to Change model as in Figure 1.

\section{Understanding and Empowerment}

Cognitive stimulation

During lockdown it was easy for people with dementia and caregivers to become quite isolated, especially if they had few family and friends to support them. Regular contact with the MC staff, especially through the telephone calls and Zoom sessions, meant that they had a different person to talk to keep them cognitively stimulated 
and engaged. These forms of contact also provided new topics of conversation and helped to give people a different focus away from their day-to-day lives. It was noticed that even when people with dementia did not particularly engage with the online sessions, they took some interest in helping caregivers to get items ready for them, such as sorting out photographs that could be shared. This in turn stimulated conversations between people with dementia and caregivers.

Similarly, people were encouraged to do activities outside of sessions and/or take photographs for a particular theme such as watching nature in the garden or baking and share them during group sessions. Many group sessions also included short quizzes or singing for people to join in with, much as would be done in a usual MC face-to-face session.

Newsletters were used by all the MCs on a regular basis, either weekly, fortnightly or monthly, with one MC producing up to 40 pages a week over four different newsletters. The newsletters had an important role to play in terms of keeping people with dementia and family caregivers cognitively stimulated by including a variety of mental activities such as word searches, quizzes, spot the difference, dotto-dot and colouring in. The photographs and short captions used within the newsletters also helped to keep faces familiar and remind everyone of previous events or trips, which in turn could stimulate reminiscence and discussions.

\section{Physical Fitness}

There was relatively limited reference to exercise and physical fitness in the interviews and focus groups although these activities are a key aspect of regular MC 
activity. Two MCs produced short video clips of seated exercises, which were shared with people with dementia and caregivers via Facebook. Three MCs also incorporated seated exercise into their Zoom group sessions. Items were included in newsletters, for example one MC advertised weekly Friday Keep Fit ('leotards not compulsory'), alongside signposting the seated exercise videos. At another MC a family member was a qualified seated exercise instructor and was involved in supporting Zoom sessions.

At the beginning of June, staff started visiting people with dementia and family caregivers in their gardens and/or going for walks. A member of staff commented that some people with dementia found it difficult to concentrate on WhatsApp calls and that going for a walk with a member of staff or volunteer was more beneficial. At one $\mathrm{MC}$ people with dementia and family caregivers engaged in bespoke garden tea dances delivered by the usual club facilitator.

\section{Optimising choice and control}

People with dementia and caregivers were asked what they would like to see included in the newsletters and for ideas for new topics and they also provided content for some of the newsletters, giving them ownership and control over their focus:

"The feedback that we get from the caregivers is that, oh, when that comes through the door, that's [name's] or whoever it is, you know. That comes through the door. That sits by his chair and then once he's had a look at it...and 
one of the women was saying, well, I just ask for permission to have a look at it because it's his." (Staff member interview).

With the Zoom sessions there was the flexibility to run them at times to suit people with dementia and family caregivers as well as staff:

“We're making phone calls; we're doing Zoom calls in the evening because some family members can't do them during the day. One of the members all three of us Zoom together with them. But, you know, it's seven o'clock on a Tuesday evening that we're doing that." (Staff member interview).

Offering different options works for different people in different ways:

"One is a husband and wife and that's WhatsApp, on a video call on a phone so it's a small screen. And then I tend to either talk to one or the other and they pass the phone between them. Whereas the Zoom call is with someone living with dementia and their son who live together. And they sit side by side and it's on a laptop and it's a three-way conversation rather than a more sort of individual conversation I have." (Staff member interview).

\section{Information and signposting}

Online sessions gave people something to look forward to, a bit of routine and structure at a time when all the days blur into each other and it is easy to lose track of time. One MC was running a Zoom session every day at $2 \mathrm{pm}$ for an hour, advertised via the newsletter and email providing a regular point of contact. 
Staff were more available than usual MC for contact outside of sessions, so caregivers could get in touch often much sooner than usual if they had issues. This regular contact via telephone calls can help to provide information and address problems before they escalate and staff can spot at an early stage when people are starting to struggle.

Regular newsletters were used to keep people up-to-date with COVID guidance/rules and plans for reopening, enabling clear, effective and timely communication. The clarity of the information around reopening was particularly appreciated by both carers and members. Referring to a form they had received, a member was able to easily see when they were due to return to their MC once it reopened.

“It's got [name's] day for the club', [manager] put this through my door.

Tuesdays 10 to 12, Thursdays [...] club at one o'clock, [...] Friday 1 'til 3. That's my week". (Member interview).

\section{Improving Emotional Well-being}

Relaxation and fun

The newsletters and email contacts often contained ideas for different activities for people to try at home, providing opportunities for people with dementia and family caregivers to do something different from their everyday lives and be engaging and fun. 
The garden visits also provided a good distraction from 24/7 caring as they gave caregivers a chance to come out of caring mode for a while. They could just relax and have a laugh with the visitor instead, which was "an enormous morale booster". The carer Zoom sessions were also a chance to relax and have fun, as the atmosphere was very relaxed with caregivers feeling comfortable enough to laugh and joke with each other.

People with dementia and family caregivers both had fun with the activities and games during the Zoom group sessions, with card bingo being one example of a fun game for all. While singing was not used by all MCs, it proved to be a particular draw with some people with dementia, even encouraging them to remain as part of a session for longer than intended:

"It started off as a couple of them wanted to go early but then when they know there's singing coming up, they stay because they say, 'oh yes, we'll stay for the singing." (Staff member interview).

The fun aspects of the sessions extended beyond the time actually online, as preparing for sessions together was also an enjoyable experience for some couples as baking or searching for photos to share sometimes triggered conversations and was something different that they could do together.

\section{Building confidence}

Some people with dementia and family caregivers felt quite isolated and worried about leaving the house and MCs were able to provide some reassurance during 
telephone calls and garden visits to reduce anxiety. Use of Zoom also helped to maintain continuity with familiar faces for when MCs would re-open.

People affected by dementia embraced the Zoom sessions, more than staff had expected:

"These are people in their eighties who have, you know, managed this technology incredibly well. It's very impressive. I think they've done better than I have trying to negotiate Zoom and Teams and all the rest of it." (Staff member interview).

\section{Opportunities to talk to others who understand}

Three of the MCs ran regular online caregiver meetings which were found to be highly supportive for family caregivers.

Some caregivers were not getting a break from caring or support during lockdown and were missing the reassurance that they were not alone in their situation and that they were not the only ones feeling guilty.

"You might laugh at this but after we come off of the iPhone, I felt honestly as if I've been out. And I thought, well, I haven't been anywhere, why should I feel like that? But I suppose relaxation and that sort of thing, just talking, listening to other people and that, you know." (Caregiver interview) 
Zoom contact was also useful for people with dementia as it gave them someone else to talk to. For example one MC was running Zoom sessions with two members of staff and one member. The carer was still there in the background but they were able to get on with something else or just sit and relax a little.

Staff and volunteers found improved relationships with people with dementia and family caregivers as the online aspect enabled increased individual contact time.

\begin{abstract}
"At the virtual Meeting Centres, I got to know her more than I would have done if I was just seeing her occasionally at the Meeting Centre because she would have been off doing other things. So at the Virtual Meeting Centres you are there all the time." (Volunteer interview)
\end{abstract}

\title{
(Re-) building Social Opportunities
}

Lack of social contact had affected people with dementia and family caregivers. There had been differing levels of contact with family, friends, neighbours, the local community and professionals during lockdown, so that in some cases the contact with $\mathrm{MC}$ managers and staff had been a significant part of their social circle. Some people with dementia and family caregivers live in quite rural areas, therefore the Zoom sessions kept people connected and helped address social isolation.

\author{
"And then loading the tablet and sending it out to them with the \\ instructions so that they can then use that to communicate. And for \\ people with dementia l've noticed it's actually huge because speaking
}


on the phone is something that they tend not to do so much anyway." (Trustee interview).

Opportunities to engage with others in a relaxed atmosphere Many other community services had stopped altogether while others were limited to telephone contact. Being able to visit people in their gardens was very useful, both in terms of providing social interaction and being able to physically see the people with dementia and caregivers and see what has changed with them and to better assess support strategies.

One MC ran hour-long Zoom sessions four days a week, rather than one session weekly, and this helped some people with dementia to recognise each other and stay in touch. Caregivers also enjoyed seeing everyone during the online sessions and liked that they are different to a telephone call.

"We have a chat at the beginning and we have a bit of singing so it's fulfilling part of the function which is just seeing other peoples' faces." (Carer interview).

Some people with dementia and family caregivers were able to use the technology provided by the $\mathrm{MC}$ and new digital skills to connect with family too:

"One of my ladies that we sent out the tablet to and she said, oh, my goodness, he was just so amazed that his family, you know, his children were there speaking to him and he could make more sense of it and far 
more engaged with it, so that's been a huge thing." (Staff member interview).

Supporting others going through similar experiences

Carer sessions were felt to be useful in terms tips and strategies for coping picked up from others. One MC saw more engagement from caregivers than they would do during face-to-face sessions.

“He's never been to the caregivers' meeting but he has said after the Zoom meetings, he has got to know us and he says he's going to come to the caregivers' group when he can - we have got a lot from him and he's got a lot from us. It's terrific really." (Staff member interview).

Relationships have grown stronger during carer Zoom sessions and some would have missed the support of the carer group if it had not been able to continue over Zoom.

\section{Effective help seeking}

Two of the MCs took on much more of a wider community role during lockdown supporting other organisations working with people with other conditions. Caregivers reported feeling able to contact someone at an $\mathrm{MC}$ if they needed help, as did the person with dementia who took part in an interview.

"[Manager] said to me 'if you ever get any problems [name], give me a ring'. I've got her phone number on the thing in front of me." (Member interview). 
MCs were still receiving new referrals during lockdown and the remote support has enabled new people with dementia and family caregivers to become part of the MC even though they had not actually 'met' anyone or visited the physical premises.

\begin{abstract}
"So I think absolutely the fact that we are able to stay in contact with these carers and give them the support while these things are happening. I think even though it's maybe not the same, kind of, structured support we could possibly have given them if it was normal times, I think the support we are offering absolutely is still key to them" (Manager interview).
\end{abstract}

\title{
Discussion
}

The study has enabled an understanding of the extent to which MCs were able to operate when physical meetings were not possible. The types of contact used and the example activities were able, to varying degrees, to facilitate the delivery of all the strategies set out in the Adjusting to Change model.

Support in usual times is provided almost entirely on a face to face basis. MCs had to find alternative ways to facilitate this support using remote approaches with different types of contact to provide activities.

The type of contacts used differed between MCs and was adjusted by the MC Managers and staff to meet the needs and preferences of their people with dementia and family caregivers. For example, some preferred telephone calls and visits to online meetings or sessions, so more effort was put into these contacts where 
appropriate. The variety of types of contact used ensured that all people with dementia and caregivers were regularly reached and supported in a way that suited them throughout lockdown.

The home garden visits enabled all of the strategies, except supporting others going through similar experiences, to be applied. This shows how important face to face contact is even though the approach only enabled staff or volunteer and one member and family carer engagement.

Group meetings and activities were only feasible by using Zoom but in using this type of contact all the strategies could be met and to some extent could replicate regular MC activity. There was an impact on the range of activities that could be provided and/or the number of people that could engage in activities. Some of the activities were quite similar in an online environment such as quizzes and card bingo although groups were smaller than during regular activity with often no more than eight participants. In the case of carer meetings these were enhanced in terms of frequency, flexibility of timing and reach. Some family caregivers would previously neither had the time nor the opportunity to meet with other caregivers as a group and as a result there was increased peer support.

The nature of the activity could also be affected, for example with the online choir participants were not able to hear others singing resulting in a reduced social and community experience. However, the alternative was that there was no choir resulting in a decrease in opportunities for cognitive stimulation, relaxation and fun, building of confidence and engagement with others in a relaxed atmosphere. 


\begin{abstract}
A new approach that was enabled via Zoom was 2-2-1 support with two members of staff and a person with dementia for chat and in some cases creative arts activities, with the family caregiver in the background. This facilitated a different type of relationship with this three-way interaction in terms of building confidence and relaxing and having fun as well as the opportunity for the family caregiver to have some personal time.
\end{abstract}

There was a trade-off between flexibility frequency and duration of contact. Some people with dementia and family caregivers had been used to up to four days of contact per week and this was reduced for some to two or three Zoom sessions a week (if they had the access to the technology) and a weekly phone call, a newsletter and an email. For some family caregivers there was the opportunity for more contact and more opportunity for peer support but this was dependent on their access to and skills in using technology.

Most people with dementia and family carers, and staff and volunteers had limited knowledge of Zoom before lockdown and had not used it to support people with dementia. Staff and volunteers had to quickly learn how to use Zoom and use it to adapt usual club activities. There was little time for reflection and no time for training.

However, a majority of those attending the MC, however, did not have the technology nor the digital skills to engage in Zoom sessions and were therefore excluded from the benefits. Managers were able to obtain technology and data but physical distancing meant that it was very difficult to support people with limited 
digital experience and skills to engage. Addressing barriers to engagement needed to be weighed up in terms of adding to the anxiety and stress of people with dementia and family caregivers. Numbers of people with dementia who might benefit from technology may be relatively low, so there is a danger of putting too much energy into one area with the technology. All but one of the MCs involved were in rural areas and there continues to be connectivity issues for many.

Recruitment of people with dementia and family caregivers to the study was lower than had been anticipated and low numbers of participants is a limitation of the work reported here. In particular this relates to hearing the voices of people with dementia. In usual times recruitment would be facilitated by the manager at the $\mathrm{MC}$ and the nature of the study and consent forms would be explained face to face. This may not translate so well over the telephone or in an email. Additionally, data collection in such times as lockdown and physical distancing is challenging. Research may not be a priority in such circumstances as a pandemic for any of the stakeholders with the focus needing more than ever to be on practical everyday matters and a pressing need to address health and well-being with doubt as to the benefits to the participants (Bartlett et al., 2019).

\section{Conclusions}

Overall this study demonstrated that MCs could continue to support people affected by dementia to adjust to change during a period when no or limited face to face contact was possible. 
MCs were able to adapt much of what they do in usual circumstances by introducing a remote support with continuity and consistency having been maintained to some extent. However, key aspects such as group activities were only open to the minority of attendees and as such the majority were digitally excluded. In some cases support was enhanced in terms of availability and flexibility as were relationships, between family caregivers and between people with dementia, family caregivers and staff but this was again largely only to the benefit of the minority. Non-technological approaches such as newsletters and garden visits were vital in terms of bridging that gap. However, it is important to recognise that remote support can cost at least as much as regular MC activity with impact on staffing (one MC had to recruit an additional member of staff) and resources such as for producing printed newsletters.

Moving forwards, a blended approach using remote and regular MC face to face methods means person-centred support could be optimised, reaching those who cannot attend MCs and could be used in rural areas to address social isolation. It would enable flexibility and consistency should there be future lockdowns. The implication is that MCs, once regular usual club and family carer sessions are permitted, should direct attention to developing member, family carer and staff digital skills. With health and social care systems stretched to their limits in dealing with the pandemic and the increased implementation of digital clinical solutions such as remote consultation and monitoring MCs could play a key role in supporting people affected by dementia with digital inclusion to access such services. Digital upskilling of MC people with dementia, family caregivers and staff and volunteers is essential not only to mitigate against the impact of a similar lockdown situation in the future but also to help address both social inclusion and digital exclusion in usual times. 
Future studies could focus on the effectiveness of remote and/or blended approaches to support. There is promise of the Adjusting to Change strategies providing a framework for the approach and which could be built into activities.

Conflict of interest declaration: The authors declare no conflict of interest. Neither the funders nor the Meeting Centre managers had a role in the design of the study; in the collection, analyses, or interpretation of data; in the writing of the manuscript, or in the decision to publish the results.

Funding: This report was funded by The National Lottery Community Fund (UK Project No.10333678). 


\section{References}

Alzheimer's Society (2020). Worst hit: dementia during coronavirus, Available at https://www.alzheimers.org.uk/sites/default/files/2020-09/Worst-hit-Dementia-duringcoronavirus-report.pdf; last accessed 03 November 2020.

Bartlett, R., Milne, R. and Croucher R. (2019). Strategies to improve recruitment of people with dementia to research studies. Dementia.18(7-8), 2494-2504. doi: $10.1177 / 1471301217748503$.

Brooker, D., Dröes, R.M. and Evans, S. (2017). Framing outcomes of post-diagnostic psychosocial interventions in dementia: the Adaptation-Coping Model and adjusting to change, Working with Older People, 21(1), 13-21. doi: 10.1108/WWOP-12-2016$\underline{0039 .}$

Brooker, D., Evans, S.C., Evans, S.B., Bray, J., Saibene, F.L., Scorolli, C., Szczesniak, D., d'Arma, A., Urbanska, K., Atkinson, T., Farina, E., Rymaszewska, J., Chattat, R., Henderson, C., Rehill, A., Hendriks, I., Meiland, F., and Dröes, R.M. (2018). Evaluation of the implementation of the Meeting Centres Support Program in Italy, Poland, and the UK; exploration of the effects on people with dementia. International Journal of Geriatric Psychiatry, 33(7), 883-892. doi: 10.1002/gps.4865.

Brown E.E., Kumar S., Rajji T.K., Pollock B.G. and Mulsant B.H. (2020). Anticipating and Mitigating the Impact of the COVID-19 Pandemic on Alzheimer's Disease and Related Dementias. American Journal of Geriatric Psychiatry, 28(7), 712-721. doi:10.1016/j.jagp.2020.04.010. 
Canevelli, M., Valletta, M., Toccaceli Blasi, M., Remoli, G., Sarti, G., Nuti, F., Sciancalepore, F., Ruberti, E., Cesari, M. and Bruno, G. (2020). Facing Dementia During the COVID-19 Outbreak. Journal of the American Geriatric Society, 68, 16731676. doi:10.1111/jgs.16644.

Dröes, R.M., Breebaart, E., Meiland, F.J., van Tilburg, W. and Mellenbergh, G.J. (2004a). Effect of Meeting Centres Support Program on feelings of competence of family carers and delay of institutionalization of people with dementia. Aging \& Mental Health, 8(3), 201-211. doi.10.1080/13607860410001669732.

Dröes, R.M., Meiland, F.J.M., Schmitz, M. and van Tilburg, W. (2004b). Effect of combined support for people with dementia and carers versus regular day care on behaviour and mood of people with dementia: results from a multicentre implementation study. International Journal of Geriatric Psychiatry, 19, 1-12.

Dröes, R.M., Meiland, F.J.M., Schmitz, M. and van Tilburg, W. (2011). An evaluation of the Meeting Centres Support Programme among people with dementia and their carers. Nonpharmacological Therapies in Dementia, 2(1), 19-39.

Dröes, R.M., Mierlo, L.D., van der Roest, H.G. and Meiland, F.J.M. (2010). Focus and effectiveness of psychosocial interventions for people with dementia in institutional settings from the perspective of coping with the disease, NonPharmacological Therapies in Dementia, 1(2), 139-161. 
Evans, S.B., Evans, S.C., Brooker, D., Henderson, C., Szcześniak, D., Atkinson, T., Bray, J., Rehill, A., Saibene, F.L., d'Arma, A., Scorolli, C., Chattat, R., Farina, E., Urbańska, K., Rymaszewska, J., Meiland, F., and Dröes, R.M. (2018). The impact of the implementation of the Dutch combined Meeting Centres Support Programme for family caregivers of people with dementia in Italy, Poland and UK. Aging \& Mental Health. doi: $10.1080 / 13607863.2018 .1544207$

Giebel C, Lord K, Cooper C, Shenton J, Cannon J, Pulford D, Shaw L, Gaughan A, Tetlow H, Butchard S, Limbert S, Callaghan S, Whittington R, Rogers C, Komuravelli A, Rajagopal M, Eley R, Watkins C, Downs M, Reilly S, Ward K, Corcoran R, Bennett K and Gabbay M. (2020). A UK survey of COVID-19 related social support closures and their effects on older people, people with dementia, and carers. International Journal of Geriatric Psychiatry. Sep 18:10.1002/gps.5434. Epub ahead of print. PMID: 32946619; PMCID: PMC7536967.

Lazarus, R.S. and Folkman, S. (1984). Stress, appraisal and coping, New York: Springer.

Mazurek, J., Szcześniak, D., Lion, K.M., Dröes, R.M., Karczewski, M. and Rymaszewska, J. (2019). Does the Meeting Centres Support Programme reduce unmet care needs of community-dwelling older people with dementia? A controlled, 6-month follow-up Polish study. Clinical Interventions in Aging, 14, 113-122. doi: 10.2147/CIA.S185683. 
Szcześniak, D., Rymaszewska, J., Saibene, F.L., Lion, K.M., d’Arma, A., Brooker, D., Evans, S.B., Evans, S.C., Chattat, R., Scorolli, C., Meiland, F., Hendriks, I., Dröes, R.M., and Farina, E. (2019). Meeting centres support programme highly appreciated by people with dementia and carers: a European cross-country evaluation. Aging \& Mental Health. doi: 10.1080/13607863.2019.1683814.

\section{Figure/Table legends}

Figure 1: UK translation into the 'Adjusting to Change Model' Table I: Type of contact and number of contacts summed across $4 \mathrm{MCs}$ Table II: Number of interviews and focus groups conducted across stakeholders 
UK translation into the 'Adjusting to Change Model' 
Table I: Type of contact and number of contacts summed across 4 MCs

\begin{tabular}{|c|c|}
\hline Type of contact & Number of contacts \\
\hline \multicolumn{2}{|c|}{ Non-technological approaches (other than the telephone) } \\
\hline Telephone call & 717 \\
\hline Post & 335 \\
\hline Home garden visits & 191 \\
\hline Other contacts & $\begin{array}{l}\text { Delivering shopping } \\
43 \text { Newsletters (most of the post contact } \\
\text { included newsletters) }\end{array}$ \\
\hline \multicolumn{2}{|l|}{ Technological approaches } \\
\hline Other contacts & $\begin{array}{l}914 \text { Emails } \\
27 \text { Facebook contacts }\end{array}$ \\
\hline WhatsApp ${ }^{1}$ or FaceTime. ${ }^{1}$ & 163 \\
\hline Zoom $^{1}$ for $1-1$ meetings & 38 \\
\hline Zoom for group meetings & $\begin{array}{l}101 \text { involving people with dementia; } \\
70 \text { just for caregivers }\end{array}$ \\
\hline $\begin{array}{l}\text { Zoom for group activity sessions - in } \\
\text { lieu of MC activity sessions }\end{array}$ & 60 \\
\hline $\begin{array}{l}\text { Total attendances by people with } \\
\text { dementia at group activity sessions }\end{array}$ & 222 \\
\hline $\begin{array}{l}\text { Average attendance at group activity } \\
\text { sessions }\end{array}$ & $\begin{array}{l}\text { 1-5 people with dementia and 1-6 } \\
\text { caregivers per session }\end{array}$ \\
\hline
\end{tabular}

${ }^{1}$ WhatsApp and FaceTime were the only applications used for video telephony. Zoom was the only video conferencing software used. These terms are used throughout the remainder of this article when addressing the relevant modes of engagement. 
Table II : Number of interviews and focus groups conducted across stakeholders

\begin{tabular}{|l|c|c|}
\hline Role at MC & $\begin{array}{c}\text { Number recruited and } \\
\text { interviewed }\end{array}$ & $\begin{array}{c}\text { Number of focus groups } \\
\text { taking place (number of } \\
\text { participants) }\end{array}$ \\
\hline Member/Family Carer & $\begin{array}{c}12(11 \text { caregivers and } 1 \\
\text { member) }\end{array}$ & $2(8)$ \\
\hline Manager & 4 & N/A \\
\hline Staff/volunteer & 7 & $2(7)$ \\
\hline Trustee & 5 & $2(8)$ \\
\hline
\end{tabular}

